\title{
Proactive responses to aggressive behaviours in out-of-home care
}

\author{
Stephen Larmar and Julie Clark
}

\begin{abstract}
Children and young people placed in out-of-home care often present with a range of complex and challenging behaviours that place significant stress on carers and other individuals involved in the placement process. The need for practical support, including the facilitation of knowledge sharing opportunities to better support carers and other health care professionals in assisting children and young people in out-of-home care, is of particular importance within the Australian context. This paper is the third in a series of four papers exploring a range of challenging behaviours that may be evidenced in children and young people placed in out-of-home care. The paper focuses on aggressive behaviours in children and adolescents and outlines a working framework to assist carers in responding appropriately to aggressive responses within the out-of-home care context.
\end{abstract}

Children and young people in out-of-home care face a range of challenges, particularly in the process of transition (Barber \& Delfabbro 2004). With the rise in children and young people entering out-of-home care contexts in Australia (AIHW 2006), the need for greater support to carers and other health professionals is paramount (Butcher 2004; Carter 2002) (for a further elaboration of the Australian context, see Larmar \& Clark 2009a). The needs of children and adolescents in the welfare system are varying, but many present with a range of complex issues that are influenced by histories of trauma, abuse and neglect (Osmond, Scott \& Clark 2008). More recent studies have reported high incidences of drug and alcohol abuse (Ainsworth \& Summers 2001), domestic violence (Kohl, Edleson, English \& Barth 2005), mental illness (Phillips 2009), poverty and its associated effects (Thomson 2003) and poor attachment (AIHW 2006) in families of children and young people entering out-of-home care. The experiences of children and adolescents drawn from such contexts can significantly impact upon their mental health (Tarren-Sweeney \& Hazel 2006), social and emotional wellbeing (Dunne \& Kettler 2006; Sawyer, Carbone, Searle \& Robinson 2007) and behaviours (Nilsen 2007). Problem behaviours are further exacerbated if the child or young person has experienced multiple placements (Newton, Litrownik \& Landsverk 2000). For carers working with vulnerable children and adolescents, the challenges associated with responding to the complex needs of such individuals are significant (Golding 2007; Herbert \& Wookey 2007).

This paper is the third in a series of four papers underpinned by Edelbrock's model of antisocial behaviours (Edelbrock 1985) which explores aggressive behaviours within the context of out-of-home care. The first and second papers focussed on oppositional and offensive behaviours respectively (Larmar \& Clark 2009a, 2009b). According to Edelbrock's conceptualisation, antisocial behaviours exist on a developmental continuum from less extreme oppositional responses, that may progress to offensive behaviours, aggressive behaviours and, finally, delinquent behaviours (Edelbrock 1985; Sanders, Gooley \& Nicholson 2000). Importantly, the model clearly indicates the merit of recognising and intervening with challenging behaviour early so as to interrupt the development of more entrenched and therefore difficult to change behaviours. The focus of 
this paper is on aggressive behaviours in children and young people in out-of-home care and provides discussion emphasising a range of considerations for carers and health professionals in considering in advance how they may respond to aggressive behaviour.

\section{A simple first step in confronting an aggressive response is for the carer to be conscious of his/her own thoughts and feelings that may be triggered by the event and to make every effort to remain calm ...}

\section{AGGRESSION}

Anger is an emotional expression common to all human beings. The expression of anger can be utilised positively as a means of asserting one's position or standing up for the rights of others (Lefkowitz, Eron, Walder \& Huesmann 1977). Conversely, anger can be destructive in intent, causing significant emotional distress and physical harm both to the angered individual and recipients of angry behaviour (Renfrew 1997). For children and adolescents, angry behaviours may take many different shapes and forms, but all expressions of anger serve some purpose in meeting the child or young person's needs (Glasser 2000). Children and young people will bring their own inner logic (way of making sense) to an interaction and it is helpful for adults to understand what that logic is, regardless of whether they accept it (Visser, Singer, van Geert \& Kunnen 2009). In terms of child development, children and young people usually have a growing capacity to emotionally regulate their behaviour which may also influence the frequency of heightened emotional responses such as anger (Peterson 2004). Given that many children and adolescents who are placed in out-of-home care have experienced abuse and neglect, there may be an even greater propensity for such individuals to display exaggerated emotions given some of the complexities of having to make sense of traumatic and displaced histories (Dunne \& Kettler 2006). For some individuals, poor attachment within the family of origin and social rejection within the individual's family and peer group in childhood may also increase the incidence of aggression in the individual (Dodge, Lansford, Salzer Burks, Bates, Pettit, Fontaine \& Price 2003). Further, the intergenerational transmission of aggressive behaviours may also impact upon some children and young people within the child welfare system given the potentially adverse circumstances experienced within families at-risk (Conger, Neppl, Jeong Kim \& Scaramella 2003). Sanders, Gooley and Nicholson (2000) elaborate on a range of factors impacting upon the development of antisocial behaviours, including aggression, and identify clear evidence that:

... conduct problems are multidetermined, with risk and
protective factors spanning individual child characteristics,
family, social and environmental factors (p. 14).

For carers working with children and adolescents in out-ofhome care, the need to understand some of the motivations underlying complex behavioural responses, as well as appropriate strategies to manage such behaviours, is paramount. Such understanding is particularly important when managing aggression, given the potentially devastating effects that destructive, angry behaviour can have on individuals and families (Renfrew 1997).

\section{A WORKING MODEL FOR RESPONDING TO AGGRESSIVE BEHAVIOURS}

In managing difficult behaviours, Sanders, Gooley and Nicholson (2000) outline a range of ways of responding to conduct problems in children. These include family interventions, child focussed treatment approaches, schoolbased interventions and psychopharmocology. The approach taken in this paper is preventative in intent and recognises that many forms of established behavioural disturbance will require referral to highly qualified professionals. Further, the approach is underpinned by social learning principles which are widely accepted and are:
... likely to be effective in reducing conduct problems to the extent that they reinforce prosocial behaviours, ignore minor misbehaviours and use systematic consequences for serious misbehaviours (Wilks, in Sanders, Gooley \& Nicholson 2000, p. 58).

Given the sometimes vast complexities associated with aggressive responses in children and adolescents, it is important to consider some helpful steps in the process of responding. A simple first step in confronting an aggressive response is for the carer to be conscious of his/her own thoughts and feelings that may be triggered by the event and to make every effort to remain calm (Temple-Plotz, Stricklett, Baker \& Sterba 2002). This is easier said than done, but will ultimately help to de-escalate a potentially challenging situation. Another consideration is the advisability of dealing with aggressive behaviour for the majority of children and young people in the specific situation in which it occurs (Polack, Gilmore, Stewart \& Mattison 1989). This ensures that the response is immediate and context-related and, therefore, potentially better understood by the individual.

Also, when confronting an angry individual, it is important for the confronter to consider their own position in the exchange to ensure that their own behaviours assist to prevent the escalation of the individual's anger and maintain the safety of all individuals involved in the situation (Balson 1995). Certain behaviours that may appear aggressive to the 
individual such as shouting or physical demonstrations of dominance, for example, are usually counterproductive to assisting an angry person to calm down. Conversely, assuming a submissive stance, such as allowing an angry person to verbally or physically dominate the exchange, regardless of the emotional and/or physical well being of another, is also unhelpful in managing that person's anger. For these reasons it is advisable to maintain an assertive position when responding to an angry person (Yogendra 1989). Acting assertively communicates to the angry individual that you are in control and will not tolerate behaviours that place you or others at-risk. To maintain an assertive position the receiver of the angry response can: assert a confident body posture (standing up straight, addressing the angry individual squarely); use a steady and confident tone of voice (avoiding shouting); and endeavour at all times to send verbal messages that avoid blaming or criticising the person, but clearly acknowledge and support the individual's frustration and articulate the receiver's concerns about any angry behaviours that may be encroaching on another person's rights (Larmar 2002).

Another factor influencing a carer's response is consideration of the impact of the response on others, as well as the context in which the angered response is occurring. If another individual is at risk of being hurt by the angry individual's behaviour, then a response may need to be more immediate or intrusive in order to maintain the safety of everyone involved. For example, if a fourteen-year-old is about to hit someone, it may be necessary to help remove either the fourteen-year-old or the potential victim to reduce the risks for all involved. It is important to also be considerate of the developmental needs of other children in the family and have realistic expectations of their behaviour and responses to other individual's behaviour. It may be important to talk to other children in the household about boundaries and ways of responding to angry behaviour in order for them to build their own strategies for managing behaviours they may find provocative. Children and young people in the household will not have the same information as carers to inform them regarding how to respond. Therefore adults need to be particularly sensitive to the child or young person's competing interests and potential lack of understanding about some of the complexities an adult would need to consider. In negotiating these sensitivities, preserving the privacy and confidentiality of the experiences of children and young people in out-of-home care is essential. Further, if the individual is expressing anger in a public space, the response may be different to one given within the confines of the family home. The public space may call for a less conspicuous response to alleviate the risk of the angry child or young person feeling embarrassed (Larmar 2002).

Another key consideration concerns what might be going on for the angry person. Any emotional expression can be
Table 1.

$A$ range of activating events and aggressive responses

\begin{tabular}{|l|l|}
\hline Activating Event & Aggressive Response \\
\hline $\begin{array}{l}\text { A favourite toy is taken from a } \\
\text { three-year-old by another child } \\
\text { during a community play event }\end{array}$ & $\begin{array}{l}\text { The child angrily hits the child } \\
\text { who has taken the toy }\end{array}$ \\
\hline $\begin{array}{l}\text { A seven-year-old girl is asked to } \\
\text { go to her room for using } \\
\text { inappropriate language }\end{array}$ & $\begin{array}{l}\text { The girl angrily shouts abuse at } \\
\text { the carer who has issued the } \\
\text { request }\end{array}$ \\
\hline $\begin{array}{l}\text { A fourteen-year-old adolescent is } \\
\text { confronted by his teacher for } \\
\text { disrupting the class group }\end{array}$ & $\begin{array}{l}\text { The adolescent yells at the } \\
\text { teacher in anger because he } \\
\text { believes that he should have the } \\
\text { right to do as he pleases }\end{array}$ \\
\hline $\begin{array}{l}\text { A five-year-old boy is taken from } \\
\text { his home and placed in a child } \\
\text { safety officer's vehicle }\end{array}$ & $\begin{array}{l}\text { The boy yells and screams and } \\
\text { tries to physically hurt the } \\
\text { workers involved in the incident }\end{array}$ \\
\hline $\begin{array}{l}\text { A fifteen-year-old adolescent is } \\
\text { asked to finish her phone call } \\
\text { immediately because other family } \\
\text { members are needing to use the } \\
\text { phone }\end{array}$ & $\begin{array}{l}\text { In anger the adolescent throws } \\
\text { an object at the carer issuing the } \\
\text { request with the intent of } \\
\text { physically hurting the carer }\end{array}$ \\
\hline
\end{tabular}

linked to an activating event that may serve to influence the individual's affective response (Smith, Lochman \& Daunic 2005). An activating event may be otherwise known as a trigger or influencing factor (related to an experience or incident in the child or young person's life) to which the individual reacts. This is particularly true in the case of angry behaviours (Renfrew 1997). It is important to remember that it is unlikely all activating events influencing the angry response will be known to those who seek to support the child or young person. Further, the child or young person may have difficulty recognising or naming the activating event and/or emotion. Table 1 lists examples of a range of aggressive behaviours and some corresponding activating events to illustrate this idea.

These examples highlight some of the motivating influences and corresponding angry responses to emphasise the importance of asking questions concerning why an individual is reacting the way they are. By attempting to understand why a child or young person is expressing anger, the carer can better determine the most conducive response to the situation.

Once these initial considerations are attended to, appropriate action can be taken. The model presented in Figure 1 on the following page represents in diagrammatic form the key elements of the discussion above.

\section{SCENARIOS TO ILLUSTRATE THE APPLICATION OF THE MODEL}

The following section presents four scenarios as a means of illustrating the application of the above model to a range of aggressive behaviours in children and young people. 
Figure 1.

Steps for proactively responding to aggressive behaviour

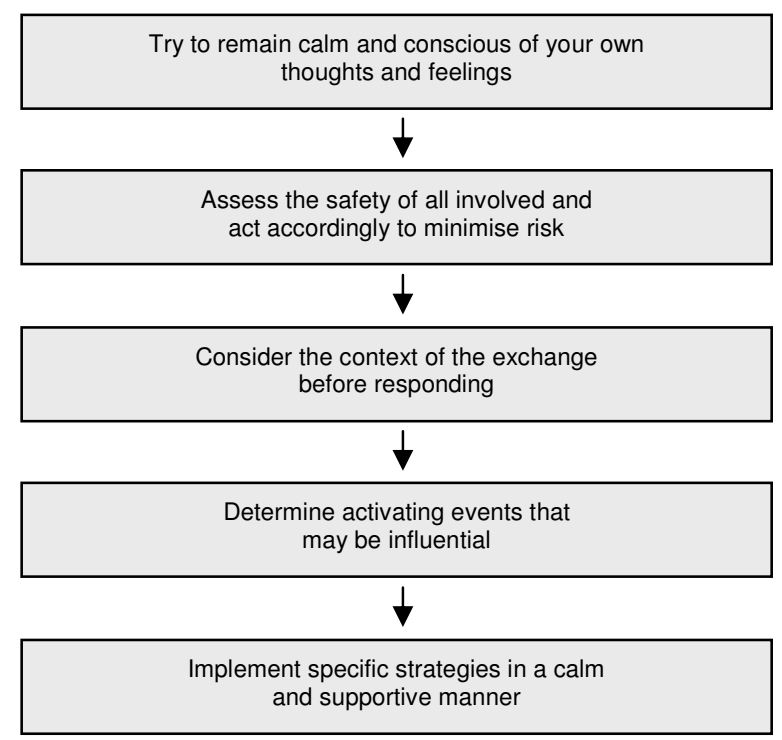

\section{Scenario One: Three-year-old Brandt}

Brandt was recently placed in care as a result of having experienced significant abuse and neglect in his family of origin. Brandt's parents are both drug dependent and during the time that Brandt was living with them, were prone to regular and severe fits of violent behaviour that placed Brandt at considerable risk of harm. Since his placement in out-of-home care, Brandt's carers have noticed that Brandt is generally cooperative but becomes extremely aggressive when asked to do something while he is engaged in playtime activities. For example, if Brandt is asked to come to the table for dinner while he is playing with his toys or watching a show on television, he immediately starts yelling or screaming and will sometimes throw an object or hit a member of the family if they are in close proximity to him. Brandt's carers are becoming quite concerned about Brandt's behaviour because of the disruption his angry responses are creating within the family.

\section{Suggested response:}

It is obvious that Brandt struggles with processes of transition within the home and so a constructive first step is to consider creative ways that might encourage Brandt to stop what he is doing and engage in a new activity. For example, the carer might provide a warning to Brandt to let him know that he will need to finish his preferred activity soon (Larmar 2002). The carer could also create a game with Brandt where he has to show how quickly he can finish what he is doing in order to undertake the new activity or task.

\section{REMAIN CALM:}

In the event that Brandt does respond aggressively, the first suggestion is to calmly request a change in behaviour. This may involve encouraging Brandt to quieten down by engaging with him at his eye level and speaking softly in a way that may serve to calm him (Porter 2003). Remaining calm may be challenging and carers need to be conscious of their own early warning signs of reactive responses, e.g. feeling angry, heightened arousal, raised voice, etc. Carers modelling behaviours which they are encouraging in young people is another proactive strategy both to assist the carer in remaining calm and to demonstrate helpful behavioural alternatives for a child or young person. For example, walking away from a situation or visualising a calm space may be helpful calming strategies (Smith, Lochman \& Daunic 2005).

\section{ASSESS SAFETY OF ALL INVOLVED:}

If Brandt is being physically aggressive towards other family members, the carer should endeavour to remove others from the situation to minimise the risk of harm.

\section{CONSIDER THE CONTEXT:}

The carer should think about the whereabouts of the event and the best course of action to take considering the context, e.g. is Brandt acting aggressively in the family home or in a public space, or are other people involved?

\section{DETERMINE ACTIVATING EVENT:}

In Brandt's situation, the activating event seems to be the request for a change in his activity. It seems that Brandt does not respond favourably to a change in activity when he is fully engrossed in a particular task.

\section{IMPLEMENT APPROPRIATE STRATEGY:}

If Brandt is playing with toys in the family home, for example, it might be appropriate to initially ignore the response in the hope that Brandt might calm down (Sanders, Cann \& Markie-Dadds 2003). In another situation, such as a playgroup context, it might be appropriate to physically remove Brandt from the play space (Temple-Plotz et al. 2002). Whatever the situation may be, the carer should maintain a supportive position but remain assertive in following through with Brandt's change of activity. If Brandt is drawing or playing with toys, it may also be appropriate to start packing up his play-things. Following each incident, once Brandt has calmed down, it would also be helpful to talk through the situation with him and explain why it is important for Brandt to cooperate during times when the carer is requesting a change in his activity (Yogendra 1989).

\section{Scenario Two: 15-year-old Brooklyn}

Brooklyn has experienced multiple placements in the five years she has been in the care system. She was originally placed in out-of-home care following investigation that confirmed that Brooklyn was being sexually abused by her stepfather. Brooklyn is generally a courteous and quiet young woman; however, she is vulnerable to experiencing 
extreme fits of rage if she feels threatened. Her anger is usually exacerbated by the provocation of Thomas, the twelve-year-old son of her carers. Thomas will often enter Brooklyn's room without permission or threaten her if she does not cooperate with him. When Brooklyn's carers try to assist her, Brooklyn hurls violent abuse at them, creating significant stress for the rest of the family, in particular, Susan, the youngest daughter in the family.

\section{Suggested response:}

An initial consideration relates to Thomas's lack of respect for Brooklyn's boundaries and her realistic need for personal space. In the first instance, it is important for Brooklyn's carers to confront Thomas about his intrusive behaviour and the need for behaviour change on his part to reduce Brooklyn's anxiety (Balson 1995).

\section{REMAIN CALM:}

When Brooklyn acts aggressively, it is important to approach her calmly and to express empathy for her frustration by using a calm and rational tone of voice and identifying with her anger over Thomas's behaviour (Metcalf 1997).

\section{ASSESS SAFETY OF ALL INVOLVED:}

If other people are occupying the space where the aggressive behaviour is occurring, it may be appropriate to ask those people to leave to assist Brooklyn in calming down. It may also be necessary to point out to Brooklyn that the current behaviour may place other people at risk as a means of encouraging her to act less aggressively.

\section{CONSIDER THE CONTEXT:}

If Brooklyn is on her own or within the confines of the family space, it may be appropriate to speak candidly about the impact of her behaviour on others. If she is in a more public space, the carer should think about the impact of their responses on Brooklyn's wellbeing (Temple-Plotz et al. 2002). For example, if Brooklyn's friends are present, the carer should consider the implications of a direct confrontation when her friends are around.

\section{DETERMINE ACTIVATING EVENT:}

In this situation, the activating event seems to be Thomas's antagonistic behaviour towards Brooklyn.

\section{IMPLEMENT APPROPRIATE STRATEGY:}

If Brooklyn is yelling at Thomas, then the carer should take the first step to remove him from the situation. The carer can then assertively request that Brooklyn settle down, making clear the impact of her behaviour on the family (Yogendra 1989). If Brooklyn continues to act aggressively, it may be appropriate to ask her to stay in her room until she is ready to talk reasonably, making clear that this is not a punitive consequence but a practical strategy to help support her in her frustrated state (Larmar 2002).

\section{Scenario Three: Seven-year-old Joseph}

Joseph entered out-of-home care just over one year ago and has remained with his original carers since placement. Joseph is an extremely introverted child who often experiences severe anxiety, particularly during times of transition and change within the out-of-home care context. On a recent trip to the local shopping complex, Joseph became lost in the crowd, but was found five minutes later in an agitated state. When reunited with his carers, Joseph began hitting both sets of parents, swore at the family's children and shouted that he no longer wanted to 'be in their family'. The incident caused a great deal of commotion at the centre and his carers were left to manage the situation.

\section{Suggested response:}

In this situation Joseph is obviously experiencing extreme stress. His feeling lost may even have conjured up feelings of abandonment which he is unable to put into words but expresses through his behaviour. This may reflect Joseph's prior experiences. It is important in this situation that his family maintain a highly supportive position to communicate to Joseph their acceptance of him.

\section{Carers modelling behaviours which they are encouraging in young people is another proactive strategy both to assist the carer in remaining calm and to demonstrate helpful behavioural alternatives for a child or young person.}

\section{REMAIN CALM:}

Because this situation is occurring in a public space, it is of extreme importance that everyone should try to remain calm. If any family members are acting in a way that may contribute to Joseph's anger, then his carer should endeavour to physically separate Joseph from anyone who may contribute to an escalated stress response. The carer may enlist another member of the family in helping Joseph - for example, by saying 'It may be useful for Joseph to have his own space to calm down. Let's go over here so that he can have some space'.

\section{ASSESS SAFETY OF ALL INVOLVED:}

In this situation it is also important to act quickly if Joseph is at risk of inflicting harm on himself or someone else. Again, it may be appropriate to keep other family members out of Joseph's proximity to minimise the risk of harm to others. 


\section{CONSIDER THE CONTEXT:}

Given the context, the carer must modify their behaviour accordingly, using a firm but non-intrusive voice to minimise the impact of the exchange both on Joseph and those around him. It may also be necessary to enlist the support of bystanders who may be willing to call for assistance from the centre staff.

\section{DETERMINE ACTIVATING EVENT:}

The activating event, Joseph getting lost, has had a serious impact on him and so the intensity of Joseph's outburst is understandable. Consideration of those elements of the situation that have caused distress will be helpful in determining the supportive behaviours that could be offered to him at this time. Responding empathically is particularly critical in a situation such as this where an individual is feeling out of control and extremely stressed (Porter 2003).

\section{IMPLEMENT APPROPRIATE STRATEGY:}

In this situation, the first step in responding directly to Joseph is to let him know that he is safe now and that he will be OK. He could be encouraged to move away to a quieter space with the carer in order to help him calm down. Minimising external stimuli is also important given that added noise and activity may add to Joseph's distress. If Joseph's physical aggression becomes unmanageable, it may also be appropriate to physically hold him and clearly explain his choices to him to maintain his own safety and the safety of others. At this point, it may be appropriate to return him to the family car or an alternative safe space where he could settle down and talk through the situation with his carer. Restraining children is a controversial issue and many behaviours can be managed by better recognition of times and events that the child or young person may have difficulty dealing with (Bell 1997). In the event that a carer physically responds to challenging behaviour, they should discuss such an incident with a worker both to explore alternatives and to adequately debrief.

\section{Scenario Four: Eleven-year-old Judith}

Judith has recently moved in with a new family given that her last placement (placement three) did not work out well for her or the placement family. Her transition into the new context has been relatively successful, in contrast to prior placements where Judith displayed ongoing antisocial behaviours that created stress for the families involved. Judith gets on well with her current carers and their two older children and seems to like the physical space and the family's pets. Generally, Judith's behaviour has been positive since her arrival. It would seem that Judith has been experiencing a 'honeymoon' period of stability in her behaviour since her placement with this family. On the family's recent visit to a relative's house, Judith became hostile towards John, a younger member of the relative's family, who tried to lock her in his parents' room. Immediately after John locked the door on Judith, she started bashing violently at the door, screaming obscenities and throwing things around the room. When the father of the visited family opened the locked door, Judith continued to verbally abuse her carers and throw objects she had found in the room. While the behaviour was difficult for those involved in the situation, her carers were aware of Judith's ongoing struggle to manage her emotions.

\section{Suggested response:}

Judith's extreme behavioural response provides a strong signpost that her being locked in the room created a stressful experience for her. In the heat of the situation it may not be appropriate to address John's parents about his behaviour, but at some point a conversation with them is recommended to alert them to the significance of John's behaviour to the situation. Whatever step is taken in managing Judith's behaviour, all responses should communicate acceptance and support for Judith.

\section{... it is important for carers to remember that they are responding to an individual's behaviour and to remind themselves that the behaviour is separate to the individual.}

\section{REMAIN CALM:}

Given that this is a stressful situation for those involved, it is important that the carer remain calm and encourage a calm response in anyone else involved in the situation. Speaking gently and supportively will also go a long way to helping Judith alleviate her stress (Temple-Plotz et al. 2002).

\section{ASSESS SAFETY OF ALL INVOLVED:}

In this situation the assistance of other adults to remove family members from the scene would be strongly advised. In this way the safety of others is assured. Acknowledging to Judith that her stress is legitimate will also help her to feel heard and supported. It is also important to assess Judith's safety to make sure that her behaviour is not placing her at risk of physical harm.

\section{CONSIDER THE CONTEXT:}

Given that the situation is occurring in someone else's home, extreme care and sensitivity should be taken to minimise the impact on other family members and to avoid Judith feeling humiliated by the event. Choosing behaviours that serve to minimise the stress of all involved is critical (Metcalf 1997).

\section{DETERMINE ACTIVATING EVENT:}

It is clear that the activating event is Judith being locked in the room. It may be worth considering future measures to 
ensure that a similar situation is avoided in the future given the distress this situation has created for Judith.

\section{IMPLEMENT APPROPRIATE STRATEGY:}

A first step in this situation would involve requesting change in Judith's aggressive behaviour, pointing out the consequences of continuing to behave in a violent way, e.g. Judith and others getting hurt, Judith feeling embarrassed by her response (Larmar 2002). If Judith continues, it may be necessary to isolate her for a short period of time, perhaps by asking others around to leave in order to prevent her from continuing to throw things at others. As part of this process, the carer can clearly encourage Judith to calm down. Once Judith's anger has abated, the carer can then talk with her to assist her in the transition out of her angry response.

The preceding section has presented a range of commonplace scenarios to demonstrate some possible ways of responding to aggressive behaviours. The critical elements that have been suggested include self-awareness and the development of assertive skills. Further, applying a familiar model such as the one suggested earlier, including remaining calm, assessing safety, considering the context and determining activating events prior to implementing chosen strategies when dealing with an angry child or young person, should assist to effectively manage an angry reaction. Finally, it is important for carers to remember that they are responding to an individual's behaviour and to remind themselves that the behaviour is separate to the individual. It is also reassuring to note that the literature is clear that anger is unlikely to remain a stable characteristic in the individual (Polack et al. 1989). Individuals experiencing feelings of anger in periods of their childhood can be assisted to make sense of their own behaviours and respond more appropriately.

It should be noted, however, that aggressive behaviour for some children and young people will indicate the need for individual treatment and support, and carers are encouraged to seek professional advice/support.

\section{CONCLUSION}

This paper has examined aggressive behaviours in children and young people in out-of-home care. Discussion focussing on aggressive behaviours was included to highlight some of the complexities associated with aggression. A framework for appropriately responding to aggressive behaviours in children and young people in out-of-home care was also outlined to better assist carers and other health professionals working in the field in the management of aggression. Finally, a series of scenarios was presented to illustrate proactive ways of responding to angered responses in children and adolescents that could appropriately translate to real-life contexts.

\section{REFERENCES}

Ainsworth, F. \& Summers, A. (2001) Family reunification and drug use by parents, Perth: Western Australian Department of Family and Children's Services.

Australian Institute of Health and Welfare (2006) Child Protection Australia 2004 - 05, Canberra, viewed 03 June 2009, $<$ http://www.aihw.gov.au>.

Balson, M. (1995) Becoming better parents, $4^{\text {th }}$ edn., Melbourne: Australian Council for Educational Research.

Barber, J.G. \& Delfabbro, P.H. (2004) Children in foster care, London: Taylor \& Francis

Bell, L. (1997) 'The physical restraint of young people', Child and Family Social Work, 1, 37- 47.

Butcher, A. (2004) Training foster carers: Upping the ante!, paper presented at the ACWA Knowledge into Action conference, August, Sydney, NSW.

Carter, J. (2002) Towards better foster care: Reducing the risks in caring for other people's children, Melbourne: The Children's Foundation.

Conger, R.D., Neppl, T., Jeong Kim, K. \& Scaramella, L. (2003) 'Angry and aggressive behavior across three generations: A prospective, longitudinal study of parents and children', Journal of Abnormal Child Psychology, 31, 2, 143-160.

Dodge, K.A., Lansford, J.E., Salzer Burks, V., Bates, J.E., Pettit, G.S., Fontaine, R. \& Price, J.M. (2003) 'Peer rejection and social information-processing factors in the development of aggressive behavior problems in children', Child Development, 74, 2, 374-393.

Dunne, E.G. \& Kettler, L.J. (2006) 'Social and emotional issues of children in kinship foster care and stressors on kinship carers: A review of the Australian and international literature', Children Australia, 31, 2, 22-29.

Edelbrock, C. (1985) Conduct problems in childhood and adolescence: Developmental patterns and progressions, unpublished manuscript.

Glasser, W. (2000) Reality therapy in action, New York: Harper Collins Publishers.

Golding, K. (2007) 'Developing group-based parent training for foster and adoptive parents', Adoption and Fostering, 31, 3, 39-48.

Herbert, M. \& Wookey, J. (2007) 'The Child Wise Programme: A course to enhance the self-confidence and behavior management skills of foster carers with challenging children', Adoption and Fostering, 31, 4, 27-37.

Kohl, P.L., Edleson, J.L., English, D.J. \& Barth, R.P. (2005) Domestic violence and pathways into child welfare services: Findings from the National Survey of Child and Adolescent Well-Being, Children and Youth Services Review, 27, 11, 1167-1182.

Larmar, S.A. (2002) Encouraging positive behaviour in young children, Australia: Early Impact.

Larmar, S. \& Clark, J. (2009a) 'Proactive responses to oppositional behaviours in out-of-home care', Children Australia, 34, 3, 30-37.

Larmar, S. \& Clark, J. (2009b) 'Proactive responses to offensive behaviours in out-of-home care', Children Australia, 34, 4, 21-28.

Lefkowitz, M.M., Eron, L.D., Walder, L.O. \& Huesmann, L.R. (1977) Growing up to be violent: A longitudinal study of the development of aggression, New York: Pergamon Press.

Metcalf, L. (1997) Parenting towards solutions: How parents can use skills they already have to raise responsible, loving kids, London: Prentice Hall.

Newton, R.R., Litrownik, A.J. \& Landsverk, J.A. (2000) 'Children and youth in foster care: Disentangling the relationship between problem behaviors and number of placement', Child Abuse and Neglect, 24 10, 1363-1374.

Nilsen, W. (2007) 'Fostering futures: A preventive intervention program for school-age children in foster care', Clinical Child Psychology and Psychiatry, 12, 1, 45-63. 
Osmond, J., Scott, T. \& Clark, J. (2008) 'The knowledge of caring: Revisiting the need for knowledge support of carers', Child and Family Social Work, 13, 262-273.

Peterson, C.L. (2004) Looking forward through the lifespan, NSW: Pearson Education.

Phillips, J. (2009) Child abuse and protection in Australia, viewed 28 May 2009, <www.aph.gov.au/library/pubs/bn/2008 2009/ChildAbuse.htm>.

Polack, G., Gilmore, C., Stewart, J. \& Mattison, S. (1989) 'A follow-up of aggressive behaviour in children', Educational Review, 41, 3, 263 270.

Porter, L. (2003) Young children's behaviour: Practical approaches for caregivers and teachers, London: Paul Chapman Publishing.

Renfrew, J.W. (1997) Agression and its causes: A biopsychosocial approach, New York: Oxford University Press.

Sanders, M.R. (1996) 'New directions in behavioural family intervention with children', in T.H. Ollendick \& R.J. Prinz (eds), Advances in Clinical Child Psychology 18, New York: Plenum, 283330.

Sanders, M.R. (1999) 'Triple P-Positive Parenting Program: Towards an empirically validated multilevel parenting and family support strategy for the prevention of behaviour and emotional problems in children', Clinical Child and Family Psychology Review, 2, 2, 71-90.

Sanders, M.R., Gooley, S. \& Nicholson, J. (2000) 'Early intervention in conduct problems in children', in R. Kosky, A. O'Hanlon, G. Martin \& C.Davis (Series Eds.), Clinical approaches to early intervention in child and adolescent mental health, Vol. 3, Adelaide: The Australian Early Intervention Network for Mental Health in Young People, 81105.
Sanders, M.R, Cann, W. \& Markie-Dadds, C. (2003) 'The Triple PPositive Parenting Programme: A universal population-level approach to the prevention of child abuse', Child Abuse Review, 12, 155-171

Sawyer, M.G., Carbone, J.A., Searle, A.K. \& Robinson, P. (2007) 'The mental health and wellbeing of children and adolescents in homebased foster care', Medical Journal of Australia, 186, 4, 181-184.

Smith, S.W., Lochman, J.E. \& Daunic, A.P. (2005) 'Managing aggression using cognitive-behavioral interventions: State of the practice and future directions', Behavioral Disorders, 30, 3, 227-240.

Tarren-Sweeney, M. \& Hazel, P. (2006) 'Mental health of children in foster and kinship care in New South Wales, Australia', Journal of Paediatrics and Child Health, 42, 89-97.

Temple-Plotz, L., Stricklett, T.P., Baker, C.B. \& Sterba, M.N. (2002) Foster care solutions: Practical tools for foster parents, Nebraska: Boys Town Press.

Thomson, J. (2003) 'This is nothing new: Child protection concerns and poverty', Children Australia, 28, 1, 4-10.

Visser, M., Singer, E., van Geert, P.L.C. \& Kunnen, S.E. (2009) 'What makes children behave aggressively? The inner logic of Dutch children in special education', European Journal of Special Needs Education, 24, 1, 1-20.

Yogendra, V. (1989) Parenting for everyone: Meeting the challenge, Queensland: T.H.E. Centre for Learning.

\section{Children Australia 2010 (Volume 35) \\ (for new subscribers only)}

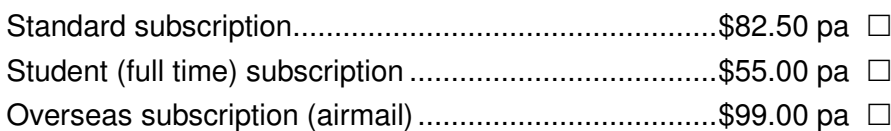

NB Standard and student subscription rates include GST

Name

If student, academic institution, course name \& student number:

Organisation

Address.

Postcode

Telephone.

Fax

Email

TAX INVOICE REQUIRED?

Cheque/money order enclosed OR Debit: Bankcard

Visa

Mastercard

Expiry date

Amount \$.

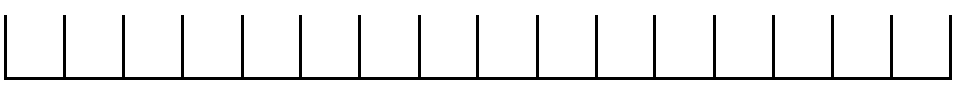

CARD NUMBER

Cardholder name.

Signature

PLEASE PRINT CLEARLY

Send to: $\quad$ Children Australia, PO Box 1312, South Melbourne, Vic 3205

Date

Enquiries: Larraine Redshaw Tel: 0396952200 Email: Iredshaw@ozchild.org.au 